\title{
UCRL-CONF-217443
}

LAW RENCE LIVERMORE N A TIO N A L LABORATORY

\section{The distribution of subsurface damage in fused silica}

P. E. Miller, T. I. Suratwala, L. L. Wong, M. D. Feit, J. A. Menapace, P. J. Davis, R. A. Steele

November 30, 2005

Boulder Damage Symposium

Boulder, CO, United States

September 19, 2005 through September 21, 2005 
This document was prepared as an account of work sponsored by an agency of the United States Government. Neither the United States Government nor the University of California nor any of their employees, makes any warranty, express or implied, or assumes any legal liability or responsibility for the accuracy, completeness, or usefulness of any information, apparatus, product, or process disclosed, or represents that its use would not infringe privately owned rights. Reference herein to any specific commercial product, process, or service by trade name, trademark, manufacturer, or otherwise, does not necessarily constitute or imply its endorsement, recommendation, or favoring by the United States Government or the University of California. The views and opinions of authors expressed herein do not necessarily state or reflect those of the United States Government or the University of California, and shall not be used for advertising or product endorsement purposes. 


\title{
The Distribution of Subsurface Damage in Fused Silica
}

\author{
P.E. Miller, T.I. Suratwala, L.L. Wong, M.D. Feit, J.A. Menapace, P.J. Davis \\ and R.A. Steele \\ University of California \\ Lawrence Livermore National Laboratory, P.O. Box 808, Livermore, CA 94550
}

\begin{abstract}
Managing subsurface damage during the shaping process and removing subsurface damage during the polishing process is essential in the production of low damage density optical components, such as those required for use on high peak power lasers. Removal of subsurface damage, during the polishing process, requires polishing to a depth which is greater than the depth of the residual cracks present following the shaping process. To successfully manage, and ultimately remove subsurface damage, understanding the distribution and character of fractures in the subsurface region introduced during fabrication process is important.

We have characterized the depth and morphology of subsurface fractures present following fixed abrasive and loose abrasive grinding processes. At shallow depths lateral cracks and an overlapping series of trailing indentation fractures were found to be present. At greater depths, subsurface damage consists of a series of trailing indentation fractures. The area density of trailing fractures changes as a function of depth, however the length and shape of individual cracks remain nearly constant for a given grinding process. We have developed and applied a model to interpret the depth and crack length distributions of subsurface surface damage in terms of key variables including abrasive size and load.
\end{abstract}

Keywords: Subsurface damage, diagnostics, optical finishing, optical fabrication

\subsection{Introduction}

Subsurface damage (SSD) refers to the residual fractured and deformed material in the near surface region of brittle optical materials. This layer of deformed and fractured material is generally the result of abrasive cutting, grinding and lapping operations that are typically used during the initial figuring and shaping of optical components. The presence of SSD is of importance to the technological application of optical glasses, ceramics and crystals. For example, it has long been recognized that the practical strength of ceramic materials is not limited by the strength of the chemical bonds making up the material or even the presence of atomic scale defects within the bulk material. Rather, the strength of brittle materials is limited by the presence of surface discontinuities. These, so called Griffith's flaws ${ }^{1,2}$, may take the form of scratches, abrasions, or 
near surface fractures such as SSD. For this reason, one typically finds that the single biggest variable governing the mechanical strength of optical ceramics is the surface finish ${ }^{3}$.

Similarly, it is generally found that the damage performance of optics subjected to intense irradiation, such as that found in high peak power laser systems, can be improved by fabricating optics in a manner which minimizes the presence of SSD in the finished optic. This is thought to be because surface fractures can serve as reservoirs ${ }^{4}$ for vanishingly small (femtogram) quantities of photo-absorbing impurities. When irradiated with a sufficiently high fluence beam, extrinsic impurities of the correct thermal size can be heated to the critical temperature required to initiate plasma formation, thus providing a means of coupling laser energy into the surface of the optic.

Due to their high removal rates, lapping and grinding are used universally for shaping optical components. Because fracture is the dominant mechanism for material removal during grinding and lapping operations, subsurface damage is inevitably introduced during the shaping process. In applications, including the finishing of low damage density optics for use on high power laser systems or the finishing of high strength components for aquatic or aerospace applications SSD must be carefully managed throughout the manufacturing process. During shaping, SSD is minimized by the use of a series of grinding steps where successively smaller abrasives are used to remove the subsurface damage introduced during previous grinding or lapping operations. The final vestiges of SSD, from grinding and lapping, can be removed by polishing, provided that sufficient material can be removed without introducing additional SSD during the polishing process.

Unfortunately, the immediate surface layer of conventionally polished optics typically consists of a thin $(\approx 200 \mathrm{~nm}$, in the case of fused silica) layer of heavily hydrated material (i.e. the Bielby layer) that effectively obscures the direct observation of SSD. The presence of subsurface cracks in most polished optics may be readily visualized by etching with a suitable acidic fluoride solution ${ }^{5,6}$. However such a technique provides no information regarding the depth or distribution of SSD.

Due to these difficulties, a variety of empirical and semi-empirical correlations have been suggested to allow one to estimate the depth of subsurface damage that remains following a given grinding or lapping operation. Generally, these correlations relate the depth of the subsurface damage to either the particle size of the abrasive used during the grinding process or to the roughness of the resultant surface.

For example, based on an extensive analysis involving a variety of optical glasses, abrasive sizes and grinding processes, including those using loose abrasives, ring tools, pellets, wheels, and saws, Lambropoulos ${ }^{7}$ has suggested that the depth of SSD (in $\mu \mathrm{m}$ ) resulting from abrasive processes lies within the bounds given by the expression:

$$
0.3 \mathrm{~d}^{0.68}<\mathrm{SSD}(\mu \mathrm{m})<2 \mathrm{~d}^{0.85}
$$

where $\mathrm{d}$ is the size, in $\mu \mathrm{m}$, of the abrasive used during the grinding operation.

Correlations have also been proposed that relate the depth of subsurface damage to the roughness of the resultant surface. Such a relationship was first expressed by Preston ${ }^{4}$, who compared the depth 
of subsurface flaws formed by grinding one surface of polished microscope slides to the depth of the exposed pits formed during grinding. Using microscopy, he found that subsurface flaws extended, into the surface, to a depth that was about three times as great as the deepest grinding pits. Later, Alenikov ${ }^{8}$ reported that the ratio of the SSD depth to the surface roughness was $3.93 \pm 0.17$ for a series of glasses and ceramics which had been ground using a range of loose $\mathrm{SiC}$ abrasives. In the late 1980s, Paul $\mathrm{Hed}^{9}$ and coworkers extended Alenikov's work by studying the relationship between surface roughness and SSD for three optical glasses (BK-7, 7940 fused silica and Zerodur) that had been ground using both fixed diamond and boron carbide abrasives. They found a ratio between SSD depth and peak-to-valley surface roughness (as measured by surface profilometry) that was significantly higher $(6.4 \pm 1.3)$ than those reported in previous studies. A considerably lower ratio has been reported by Lambropoulos ${ }^{10}$ et. al. who report a ratio of less than two. The differences in the ratio reported by these workers are likely due to the differences in the methodologies used to estimate both peak-to-valley roughness and SSD depth. For example, Hed used a stylus profilometer to estimate surface roughness while Lambropoulos used a white light interferometer. One would expect that spatial scale length, and thus the apparent surface roughness of each measurement would differ considerably.

Similarly, several experimental methods have also been used, by those interested in the fabrication of precision optics, to estimate SSD depth. These include the taper polishing technique, such as that used by $\mathrm{Hed}^{9}$, and the dimple technique where either a steel ball and a diamond abrasive ${ }^{11,12}$ or magnetorheological finishing (MRF) ${ }^{13,14}$ is used to locally remove material, thus allowing subsurface fractures to be visualized as a function of depth. Historically, the use of these techniques has been restricted to relatively small areas $\left(\mathrm{a}\right.$ few $\mathrm{mm}^{2}$ ) which makes it difficult to characterize the statistical distribution or nature of the SSD found following typical abrasive processing. In the present work we have used MRF to taper polish relatively large areas of several fused silica substrates that had previously undergone abrasive grinding. Through the use of photomicroscopy and image analysis, we have characterized both the crack depth and crack length distributions and related these distributions to one another using relationships from indentation fracture mechanics. The area of the wedge that is used to characterize subsurface damage, in the present technique, is significantly larger than that used by the dimple technique. Therefore MRF taper polishing provides both a means of characterizing the distribution of subsurface damage and a significantly more robust measurement of the maximum extent of SSD.

\subsection{Experimental}

A series of six $10 \mathrm{~cm}$ diameter 7980 (Corning Glass Works, Corning, NY) fused silica blanks, which had previously been polished, were ground using either bound diamond abrasives or loose $\mathrm{Al}_{2} \mathrm{O}_{3}$ abrasive. Generous material removal was performed in each case to ensure that any residual SSD from previous operations was completely removed. A seventh optic was sandblasted using $300 \mu \mathrm{m}$ alumina grit. The sizes of the abrasives used in preparation of the remaining samples, together with other relevant experimental details, are summarized in Table 1. Following preparation, the peak to valley surface roughness of each surface was measured using a KLA Tencor model P-10 stylus profilometer, by making a series of $5 \mathrm{~mm}$ scans in four randomly selected areas. 
The method used to characterize the SSD, in each sample, is shown schematically in Figure 1 and has been described in detail elsewhere ${ }^{15}$, thus only a brief description will be given here. Following abrasive processing, the SSD, as a function of depth, was revealed by using an MRF (QED Technologies, Rochester NY) to polish an approximate $50 \mathrm{~cm}^{2}$ taper into the surface of each optic. The depth and slope of each taper was then characterized by surface profilometery. The taper depths for each sample depended on the sample preparation and ranged between $\approx 20$ and $110 \mu \mathrm{m}$ for the sample set shown in Table 1. Following taper polishing, each sample was etched in 20:1 buffered oxide etch (BOE) for several minutes to allow visualization of the subsurface fractures. Finally, a series of photomicrographs were electronically recorded at magnifications of $75 \mathrm{x}$ or $300 \mathrm{x}$, along the polished taper, thus allowing the compilation of a series of micrographs documenting the SSD as a function of depth into each sample.

\subsection{Results}

Several representative micrographs of the surfaces, of the ground samples described above are shown in Figure 2. As shown in this figure, the near surface region of each of the ground optics consists of a complex network of overlapping fractures which are impossible to characterize individually. Figure 3 presents a collage of a small number of micrographs typical of those observed as one progresses along the etched taper of a previously ground sample. There are several notable features that are apparent in Figure 3. First, there is a depth below which no damage or additional fractures are seen. This observation is consistent with previous work ${ }^{13}$ and illustrates that the MRF polishing tool itself does not propagate damage during the polishing process. Secondly, although the density of fractures changes markedly as a function of depth, the size and shape of the isolated fractures do not change significantly, for each grinding process.

Each of the isolated flaws or fractures shown in Figure 4, or throughout the near surface region of the optic, can be characterized both in terms of the depth (c) that it extends into the work piece and in terms of the length (L) of the arc that the fracture leaves on the surface of the substrate (see Figure 5). The distributions of crack depths and crack lengths, for each of the samples in Table 1, are shown as Figures 6 and 7 respectively. Note that the ordinate of the crack depth distribution (Figure 6 ) is given in terms of obscuration (i.e. crack area fraction relative to observed area), rather than number of cracks. This was done to allow the distribution to extend into the near surface region which is characterized by a heavily overlapping network of fractures.

\subsection{Indentation Fractures}

\subsection{Discussion}

During grinding, material removal results from the accumulation of vast numbers of abrasive induced fractures. Individual fractures such as those shown in Figure 4, are typical of the type of flaws found in the subsurface layer of all ground surfaces and were originally described by Preston as "chatter flaws" . In contemporary terms, such fractures can be classified as indentation fractures ${ }^{16}$ which result from the contact of a hard indenter (an abrasive particle) and a brittle surface (the work piece). It is useful to distinguish between fractures that occur under the influence of a blunt indenter and those that occur in response to a sharp indenter. When the indenter is sufficiently blunt, the 
substrate responds as a purely elastic material. A normally loaded static blunt indenter results in the formation of a classic Hertzian cone crack (see Figure 8a).

Once such a fracture has been initiated, it will grow to a depth $\left(\mathrm{c}_{\mathrm{h}}\right)$ which is dependent only on the load (P) impressed upon the indenter and the material properties of the substrate ${ }^{16}$ :

Where:

$$
c_{h}=\left(\frac{\chi_{h} P}{K_{I c}}\right)^{2 / 3}
$$

$\chi_{h} \quad$ is the a dimensionless constant dependent on the materials properties of the substrate.

For fused silica, Lawn ${ }^{16}$ give a value of 0.03 as the Hertzian growth constant

$P \quad$ is the load

$K_{I c} \quad$ is the fracture toughness

For a given load, as the radius of curvature of the indenter becomes smaller, the local pressure in the contact zone beneath the indenter rises. When the contact pressure exceeds a critical value, material directly below the indenter plastically deforms. In such cases, rather than a cone crack, radial cracks (Figure 8b) and lateral cracks (Figure 8c) are formed. Since lateral cracks have the potential to vent to the surface (see Figure 8c), cracks of this type of fracture represents the most efficient means of removing material from the surface of the work piece. As a result, conditions that favor lateral crack formation, such as sharp abrasives (indenters), would be expected to lead to more rapid material removal. In contrast, a network of intersecting cone or radial cracks must be present for material removal to take place. This need for an intersecting network of cracks explains the relative difficulty in removing material by grinding from previously polished glass surfaces compared to those that have previously been ground ${ }^{5}$.

While one would expect that lateral cracks would be the most effective at removing material, SSD damage would be expected to be dominated by radial or cone cracks.

Once initiated, the depth of a radial crack is governed by an expression which is analogous to Equation 1, with $c_{r}$ replacing $c_{h}$ and $\chi_{r}$ replacing $\chi_{h}$. For fused silica the radial growth $\left(\chi_{r}\right)$ constant $^{17}$ is about $60 \%$ smaller $(0.030$ vs 0.019$)$ than the Hertzian growth constant $\left(\chi_{h}\right)$. Thus, if one were to have two equally loaded indenters, one sharp and one blunt, one would expect that the length of the cone crack associated with the blunt indenter, would be about $35 \%$ larger than the length of the radial crack associated with the sharp indenter.

Grinding does not, of course, occur as a series of static indentations. Rather, in addition to the normal load, a tangential load is also present representing the component of the abrasive's motion that is parallel to the surface of the work piece. The fractures that are formed when an indenter moves along the surface of a brittle material are analogous to those formed by static indentation and have been described by Lawn $^{18}$ The addition of a tangential load increases the tensile stress at the trailing edge of the contact zone between the particle and the substrate. This increased tensile component dramatically reduces the load required for crack initiation and results in the preferential formation of fractures at the trailing edge of the indenter (Figure 9). While the presence of the tangential load greatly reduces the load required to initiate a crack, the tangential load has only a 
modest effect on the depth of the crack. In the case of a blunt indenter sliding across a surface the depth $\left(c_{t h}\right)$ of the resulting fracture is given by $\operatorname{Lawn}^{18}$ as:

$$
c_{t h}=\left[\left(\frac{\chi_{h} P}{K_{I c}}\right)\left(1+\mu^{2}\right)^{2}\right]^{2 / 3}
$$

Under frictionless conditions $(\mu=0)$, the depth of the trailing fracture reduces to that of the static indentation fracture. One would expect that the presence of preexisting fractures might modify the local stress distribution in the vicinity of a given abrasive - surface interaction. Nonetheless, indentation mechanics provide a useful model for understanding the factors and scaling laws associated with the material removal process. Thus, the collection of "chatter flaws" first described by Preston and apparent in the present data, might well be termed trailing indentation fractures.

Due to the large number of particles involved and the dynamic nature of the grinding process, it is beyond our grasp to use expressions such as Equations 1 or 2 to estimate the depth of subsurface damage caused by a given grinding operation. To do so would require a priori knowledge of the time dependent particle loading during the grinding process. It is instructive, however, to estimate the minimum fraction $\left(\mathrm{f}_{\mathrm{p}}(\mathrm{c})\right)$ of the total load $\left(\mathrm{P}_{\mathrm{T}}\right)$ that was present on a given particle to result in the growth of a crack to a given depth. Substituting the relationship:

$$
P=f_{p} \cdot P_{T}
$$

into Equation 2 and rearranging gives:

$$
f_{p}(c)=\frac{K_{I c} c_{h}{ }^{3 / 2}}{x_{h} P_{T}\left(1+\mu^{2}\right)^{2}}
$$

In the case of the Sample F, which was ground with $9 \mu \mathrm{m}$ loose abrasive, the maximum subsurface damage depth (Figure 6) was observed to be $\approx 6 \mu \mathrm{m}$. Evaluating Equation 4 , assuming frictionless system $(\mu \approx 0)$, one finds that for a crack to have grown to the maximum SSD depth, a single abrasive particle must have carried, at one point in time, about $1 \%$ of the total $(25 \mathrm{~N})$ load. If one further assumes abrasive particles pack beneath the optic with a fill fraction of $\approx 0.1$, then a 4 " part would be expected to have on the order of 100 million particles beneath it at any given time. One is left with the intuitively responsible conclusion that the maximum SSD depth results from the total instantaneous load being distributed over an extraordinarily small (on the order of 1 in a million) fraction of the total abrasive particles that are present at any given time.

The most straightforward means of altering the per-particle load is by modifying the distribution of particle sizes present in the grinding process. Consider for example the damage depth curves, for samples F, D and J shown in Figure 10. The preparation of samples F and D have previously been discussed. Sample $\mathrm{J}$ was prepared in a similar manner except that the grinding slurry was prepared by spiking the base slurry of $9 \mu \mathrm{m} \mathrm{Al}_{2} \mathrm{O}_{3}$ (Mirogrit WCA9T) with $0.1 \mathrm{wt} \%$ of $15 \mu \mathrm{m} \mathrm{Al}_{2} \mathrm{O}_{3}$ (Mirogrit WCA15T). As shown in Figure 10, the presence of even a small fraction of nominally $15 \mu \mathrm{m}$ particles effectively increases the maximum per-particle loading, thus significantly increasing the depth of the SSD layer. That is, the presence of only a few $15 \mu \mathrm{m}$ particles caused significantly 
more damage than when the entire abrasive population consisted of $15 \mu \mathrm{m}$ particles. The preceding example illustrates both the importance of ensuring the uniformity in the size of grinding media ${ }^{19}$ and the importance in excluding impurities (rogue indenters) from finishing operations.

\subsection{The fracture depth distribution}

During a grinding process, new surface fractures are continually being formed while the depth of previously formed fractures are continually being reduced and ultimately eliminated as material is removed from the surface of the work piece ${ }^{20}$. In the case of a grinder under constant load, one would expect that the maximum fracture depth (e.g. maximum depth of SSD) would be dominated by those fractures that were both formed late in the process, and as the result of highest per particle loading.

Experimentally, one finds that the obscuration resulting from subsurface cracks (Figure 5) decays exponentially over several orders of magnitude. Such an exponential decay can not, of course, continue without bound. Aside from a small frictional contribution, Equation 2 implies that for a given substrate, the maximum depth of subsurface damage corresponds simply to the fracture associated with most heavily loaded particle. It is this maximum depth that is responsible for the truncation of the exponential decay seen in Figure 5, and corresponds to the maximum SSD depth.

\subsection{The fracture length distribution}

As has been noted above, the length of each of the isolated fractures associated with a given abrasive process (see Figure 4) lie within relatively narrow bounds. The experimentally determined cumulative distribution $(\mathrm{F}(\mathrm{L}))$ of crack lengths from each process can be fit to an exponential function the form:

$$
F(L)=1-A e^{\left(\frac{-L}{\prec L \succ}\right)}
$$

Where:

$$
\begin{array}{cl}
\mathrm{L} & \text { is the crack length } \\
\prec \mathrm{L} \succ & \text { is the estimated average crack length } \\
\mathrm{A} & \quad \text { is an arbitrary fitting parameter }
\end{array}
$$

A summary of the fitting parameters associated with each of the shaping processes is shown in Table 2. As shown in Table 2, and Figure 4, each process has a crack length distribution that is characteristic of the abrasive size used during that process. This reflects the physical overlap between the substrate and the abrasive during the initiation and growth of the resultant crack. In the case of an idealized, hard, elastic, spherical abrasive, interacting with an elastic substrate, the size of the overlap is given by the Hertzian contact zone ${ }^{21,22}$.

$$
a=\left(\frac{4}{3} \frac{k}{E_{s}} \operatorname{Pr}\right)^{\frac{1}{3}}
$$


Where:

$\begin{array}{ll}\mathrm{a} & \text { is radius of the circle of contact } \\ \mathrm{r} & \text { is the radius of the particle } \\ \mathrm{P} & \text { is the load applied to the indenter } \\ \mathrm{k} & \text { is a contact parameter given by the expression: }\end{array}$

Where:

$$
k=\frac{9}{16}\left[\left(1+v^{2}\right)+\frac{E}{E_{s}}\left(1+v_{s}^{2}\right)\right]
$$

$v$ and $v_{\mathrm{s}} \quad$ are Poisson's ratio of the indenter and the substrate respectively.

$\mathrm{E}$ and $\mathrm{E}_{\mathrm{s}} \quad$ are Young's moduli for the indenter and the substrate respectively.

A static Hertzian fracture would be expected to have a radius the size of the contact zone. In the case of a trailing indentation, a crack forms only around a fraction of the circumference of the contact zone, see for example Figure 9. If one assumes that the fracture forms over only a quarter of the circumference ${ }^{18}$ of the contact zone, the following expression provides an estimate of the length of the resultant crack:

$$
L \approx \frac{\pi}{2}\left(\frac{4}{3} \frac{k}{E_{s}} \operatorname{Pr}\right)^{\frac{1}{3}}
$$

\subsection{The relationship between the fracture depth and fracture length distributions}

The most straight forward means of estimating the maximum extent of subsurface damage, using the MRF wedge polish technique, is to plot the obscuration as function of depth as has been done in Figure 6. Using the cumulative obscuration distribution, to make such an estimate generally requires that the depth of the taper exceeds the maximum depth of subsurface damage. Given that both the fracture depth and the fracture length distributions describe the same population of cracks, one might expect that information from the crack length distribution can be used to describe the distribution of crack depths, and thus the observed obscuration.

Recall that for a given substrate and abrasive, the depth of subsurface damage is a function of a single parameter, that is the distribution of loads $(P)$ that are imposed on each of the ensemble of abrasive particles (indenters). The crack length distribution, however, is a function of two parameters; the distribution of both effective particle sizes $(d=2 r)$ and the resulting distribution of particle loads $(P)$. Note that the "effective" particle size distribution represents a subset of the parent particle size distribution in that it represents only that portion of the parent distribution that results in the initiation and growth of fractures.

One would expect that the total load $\left(\mathrm{P}_{\mathrm{T}}\right)$ imposed on the surface of a substrate during grinding would be apportioned between the various abrasive particles present as a simple function of the dimension of each particle. If one assumes that the fraction of the total load $\left(\mathrm{P}_{\mathrm{T}}\right)$ that is transmitted from the lap to the substrate via a given particle is a linear function of the penetration of the particle into either the lap or substrate, then the load on a given particle $\left(\mathrm{P}_{i}\right)$ can be expressed as a function of 
the size of a particle size $\left(\mathrm{d}_{\mathrm{i}}\right)$ relative to that of a normalizing particle size characteristic of the abrasive $\left(\mathrm{d}_{\mathrm{c}}\right)$ used:

$$
P_{i}(d)=\frac{P_{T}}{N_{L}}\left(\frac{d_{i}}{d_{c}}\right)
$$

Where the quantity $\mathrm{P}_{\mathrm{T}} / \mathrm{N}_{\mathrm{L}}$ represents the average load per particle.

One can express the distribution of crack lengths as a fractional, $f(L)$, rather than as a cumulative distribution:

$$
f(L)=\frac{d F(L)}{d L}
$$

Using Equation 9 allows particle size to be eliminated from Equation 8 allowing one to express the length of indentation fractures (L) as a function of one, rather than two ( $\mathrm{P}$ or $\mathrm{r}$ ) variables. When such a substitution is made which eliminates the particle size (r) from Equation 8, one finds that both the length (L) and depth (c) of the fracture scale as the $2 / 3$ power of the load (P). Moreover using this model, one finds that the ratio of the fracture length and depth are linearly related to one another by the expression:

$$
\Omega=\frac{L}{c_{h}} \approx \frac{\pi}{2}\left(\frac{K_{I c}}{\chi_{h}}\right)^{2 / 3}\left(\frac{2 k N_{L} d_{c}}{3 E P_{T}}\right)^{1 / 3}
$$

Since the crack length can be expressed as a function of a single variable, and associated constants, one can express the crack length distribution $(\mathrm{F}(\mathrm{L}))$ as a function of load $(\mathrm{P})$. By making this change in variables one to express a fractional load distribution $\frac{d F(P)}{d P}$ in terms of the fractional crack length distribution:

$$
\frac{d F(P)}{d P}=\frac{d F(L)}{d L} \cdot \frac{d L}{d P}
$$

Similarly, by substitution of the appropriate variables and application of the Fracture Mechanics derived scaling law, relating crack depth and load (Equation 1 or 2), it is easy to show that the fractional crack depth distribution is related to the fractional distribution of crack lengths by the general expression:

$$
\frac{d F(c)}{d c}=\frac{d F(L)}{d L} \cdot \frac{d L}{d P} \cdot \frac{d P}{d c}
$$

The fractional distribution of crack depths can in turn be multiplied by the width (w), length and number $(n)$ of cracks allowing a fractional obscuration $(\mathrm{o}(\mathrm{c}))$ to be expressed as:

$$
o(c)=\frac{d F(c)}{d L} \cdot \frac{d L}{d P} \cdot \frac{d P}{d c} \cdot w \cdot n \cdot L(c)
$$


Integration of the fractional obscuration $(\mathrm{o}(\mathrm{c}))$ allows us to express the cumulative obscuration $(\mathrm{O}(\mathrm{c}))$

$$
O(c)=\int_{c}^{c_{\max }} o(c) \cdot d c
$$

Although the process outlined above may be carried out numerically, when the cumulative crack length distribution is expressed in the form of Equation 5, the cumulative obscuration is found to be of the form:

$$
\mathrm{O}(\mathrm{c})=\mathrm{Awn}\left[\Omega\left(\mathrm{c}+\frac{\prec \mathrm{L} \succ}{\Omega}\right) \mathrm{e}^{\left(\frac{-\mathrm{c} \Omega}{\prec \mathrm{L} \succ}\right)}-\left(\mathrm{L}_{\max }+\prec \mathrm{L} \succ\right) \mathrm{e}^{\left(\frac{-L_{\max }}{\prec \mathrm{L} \succ}\right)}\right]
$$

As shown in Equation 16, the cumulative obscuration, $\mathrm{O}(\mathrm{c})$, is the difference of two exponentials. The first half of Equation 16 decays as an exponential of crack depth, while the second exponential function is a constant for a given crack length distribution.

The cumulative obscuration, as expressed in Equation 16, has been fit to each of the experimentally measured distributions (see Figure 11). The values of the fitting parameters used in each case are shown in Table 3.

\subsection{Correlations of Subsurface Damage with Surface Roughness and Crack Length}

As noted above, Preston ${ }^{5}$ first described an empirical correlation between surface roughness and the depth of subsurface damage. The physical basis for such a correlation may be the result of the characteristics of the fractures which lead to subsurface damage and surface morphology, respectively. One would expect that the maximum depth of SSD would be dominated by either Hertzian or radial cracks while material removal, and thus surface morphology, might well be dominated by the depth of lateral cracking. Due to the slightly larger growth constant for the Hertzian, we will assume that the depth of the SSD is proportional to the depth of fractures of this type.

The depth that a static lateral crack $\left(c_{1}\right)$ will grow is also related to the load on the indenter ${ }^{23}$. Specifically:

$$
c_{\ell}=\chi_{1}\left(\frac{E_{s}}{H_{s}}\right)^{2 / 5}\left(\frac{P}{H_{s}}\right)^{1 / 2}
$$

Where:

$\chi_{1}$ is a lateral growth constant that is dependent on the materials properties of the substrate $\mathrm{H}_{\mathrm{s}}$ is the indentation hardness of the substrate

And

$E_{s}$ is the modulus of the substrate 
The ratio of Equation 17, which describes the depth of a lateral fracture, and Equation 1, which describes the depth of a Hertzian fracture, results in an expression that would be expected to be proportional to the ratio of SSD and surface roughness.

$$
\frac{S S D}{\delta} \propto \frac{c_{h}}{c_{l}}=\left(\frac{\chi_{h}{ }^{2 / 3}}{\chi_{\ell}}\right)\left(\frac{H_{s}}{K_{I c}}\right)^{2 / 3}\left(\frac{H_{s}{ }^{7 / 30} P^{1 / 6}}{E_{s}^{2 / 5}}\right)
$$

This expression is similar to one that has been given by Lambropoulos ${ }^{24}$ et. al. However in the present case, we have assumed that the depth of the subsurface damage is proportional to the depth of Hertzian, rather than radial crack, and that the surface roughness is proportional to the depth of the lateral cracks, rather than the size of the plastically deformed zone as was assumed by Lambropoulos. As shown in Equation 18, this ratio is dominated by the materials properties of the substrate and only a weak $\left(\mathrm{P}^{1 / 6}\right)$ function of the conditions under which the grinding is performed (e.g. applied load).

The correlations that we have observed between surface roughness and the average and the maximum extent of SSD are shown in Figure 12. As shown in Figure 12, the present work indicates the maximum SSD is about 9 times as deep as the peak to valley roughness, as measured by surface profilometery. Unfortunately there is often a great deal of uncertainly associated with the experimental measurement of peak to valley roughness. In the present set of data, for example, replicate measurements $(n=4)$ typically varied by $\pm 40 \%$ relative to the mean. As an alternative means of estimating the depth of subsurface damage we have also plotted (Figure 13) both the average $\left(<\mathrm{c}>\right.$ ) and the maximum $\left(\mathrm{c}_{\max }\right)$ fracture depth as a function of the average crack length $<\mathrm{L}>$, as suggested by Equation 11. As shown in Figure 13, the average fracture depth is found to be 0.35 times the average crack length, while the maximum fracture depth (SSD) is about 2.8 times the average fracture length. Such a correlation can be used to estimate either the average or maximum extent of subsurface damage given a population of isolated fracture on the surface of an optic.

\subsection{Summary}

We have directly measured and characterized the subsurface damage found in a series of fused silica samples that were subjected to sandblasting and single grinding processes typical of those used during optical fabrication (e.g. loose abrasive grinding and fixed abrasive grinding using metal and resin bond abrasives). The present results indicate that isolated subsurface fractures, caused during grinding, can be described as trailing indentation fractures. Although the density of cracks decays exponentially as a function of depth, the basic shape and length of individual cracks, remains similar throughout the subsurface damage layer. The distributions of crack lengths also show an exponential dependence and are related to the size of the abrasive that created the fractures. The crack length and crack depth distributions can be related to one another through the use of a simple model based on indentation mechanics.

Indentation mechanics also suggest, and experimental data confirm, that the maximum depth of the subsurface damage layer results when abrasive particles carry abnormally high fractional loads. This emphasizes the importance of monodispersed particle size distributions and the exclusion of rogue 
particles which can result in high per particle loading, thus increasing the depth of the subsurface damage layer.

Consistent with previous workers, we find that the depth of SSD correlates with peak to valley roughness. We suggest that such a correlation is the result of difference in the type of indentation fractures which dominate SSD and surface removal respectively. As an alternative means of estimating the depth of subsurface damage we suggest a correlation between average crack length and SSD.

\subsection{Acknowledgments}

The authors gratefully acknowledge the technical assistance of Wayne Whistler and James Embree in the preparation of the grinding samples used in this work.

This work was performed under the auspices of the U.S. Department of Energy by the University of California, Lawrence Livermore Laboratory under Contract No. W-7405-Eng-48 with the LDRD program. 


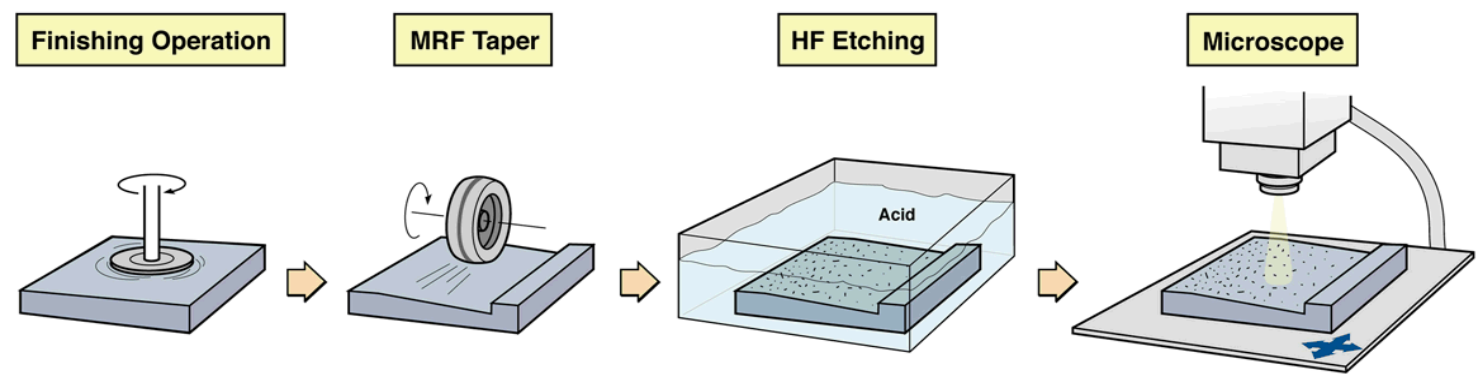

Figure 1: Schematic representation of the method used to characterize subsurface in this work.
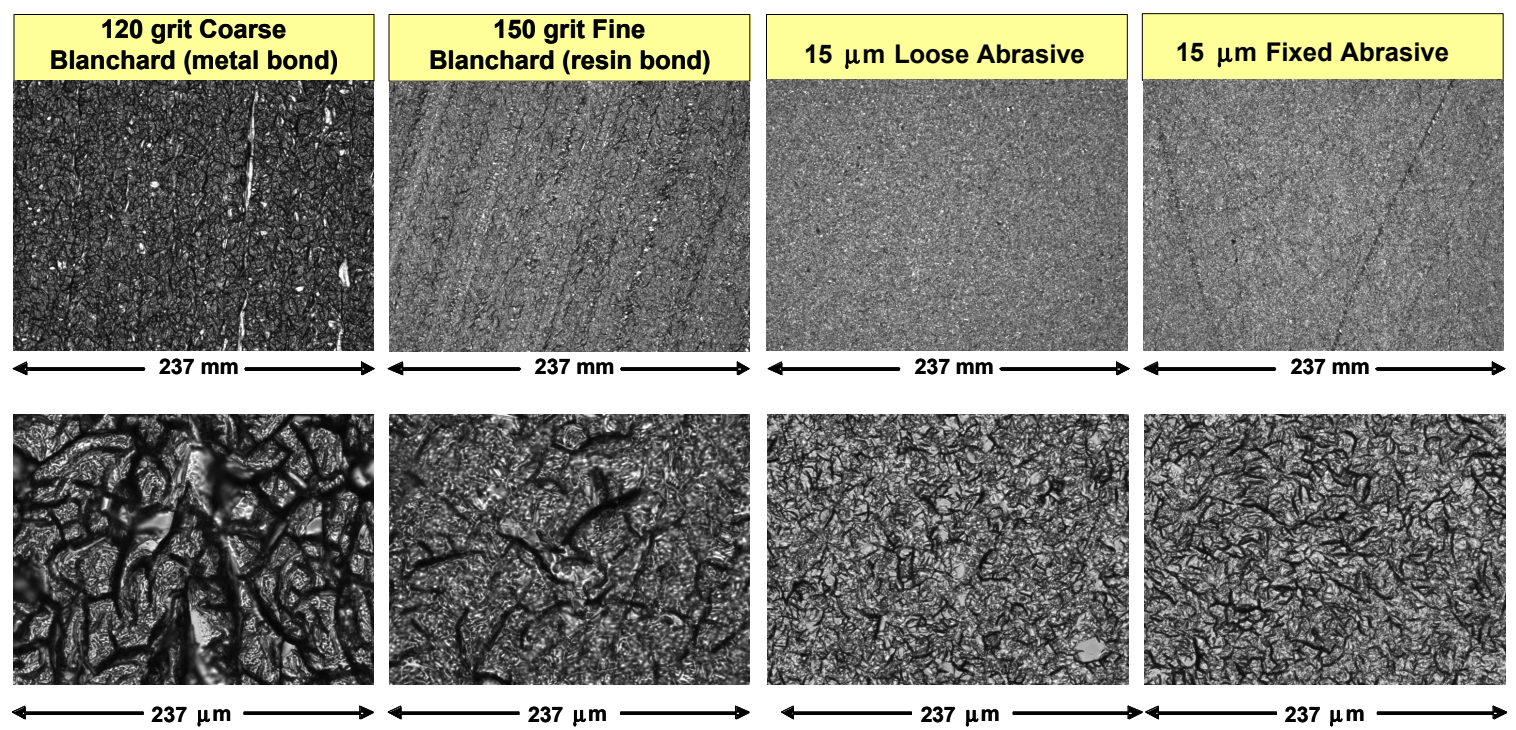

Figure 2: Typical appearance of near surface cracks on ground fused silica surfaces. 


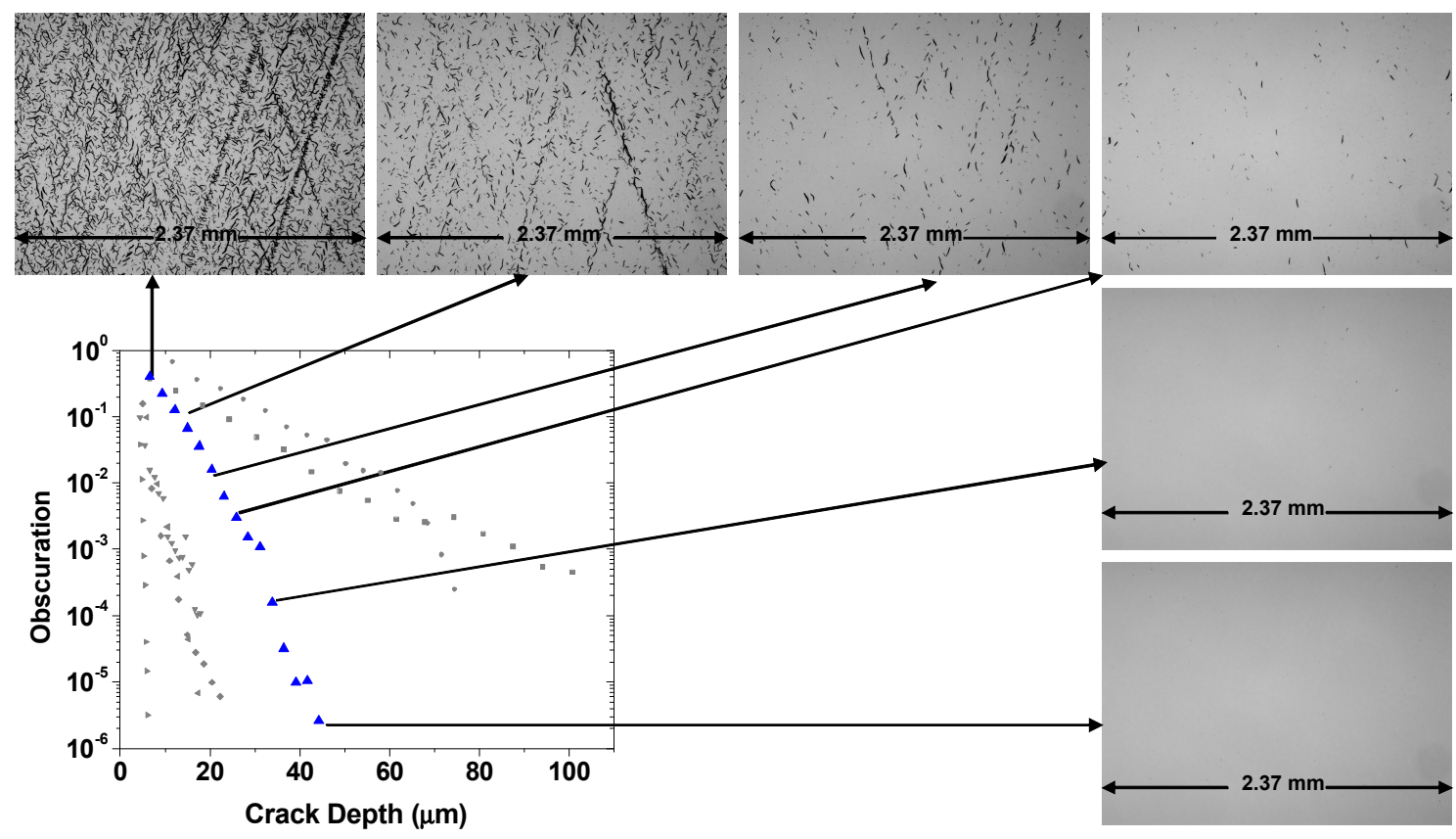

Figure 3: Fracture morphology as a function of depth into the ground surface
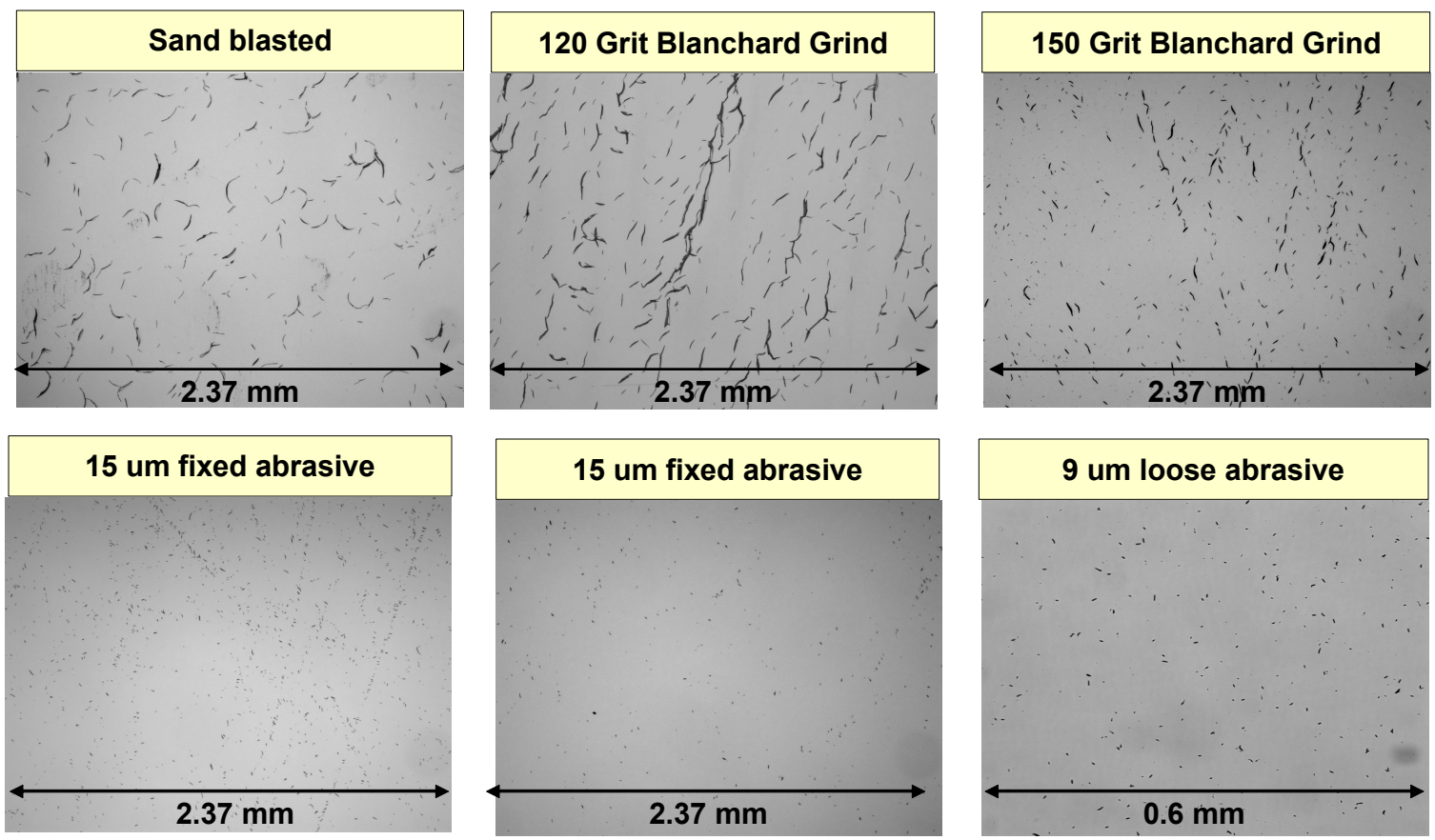

Figure 4: Isolated and near isolated fractures exposed by MRF taper polishing and subsequent BOE etching. 


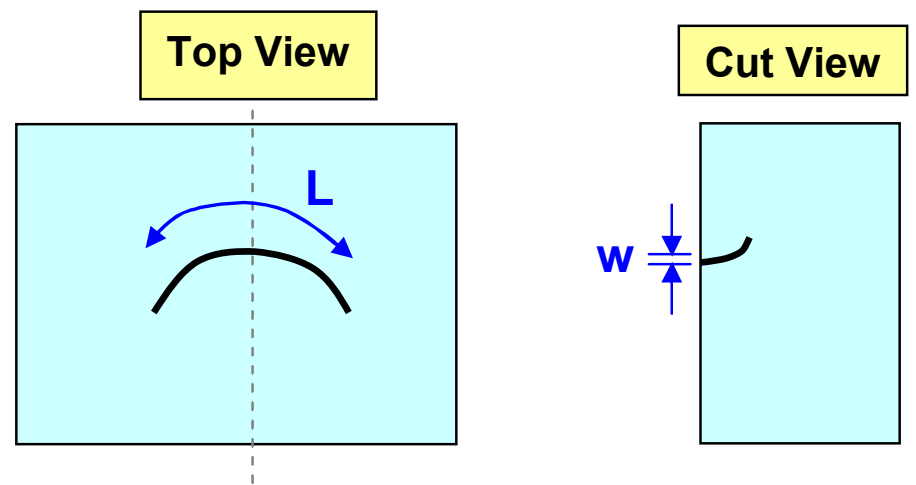

\section{Side View}

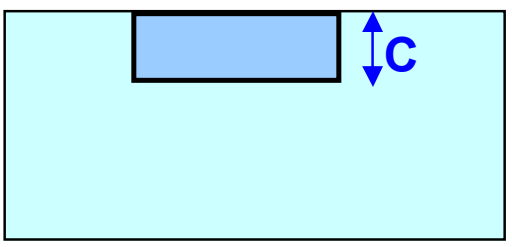

Figure 5: Schematic representation of crack length and depth nomenclature used in this work. In the present work the width of the crack is typically governed by the time used to etch the cracks.

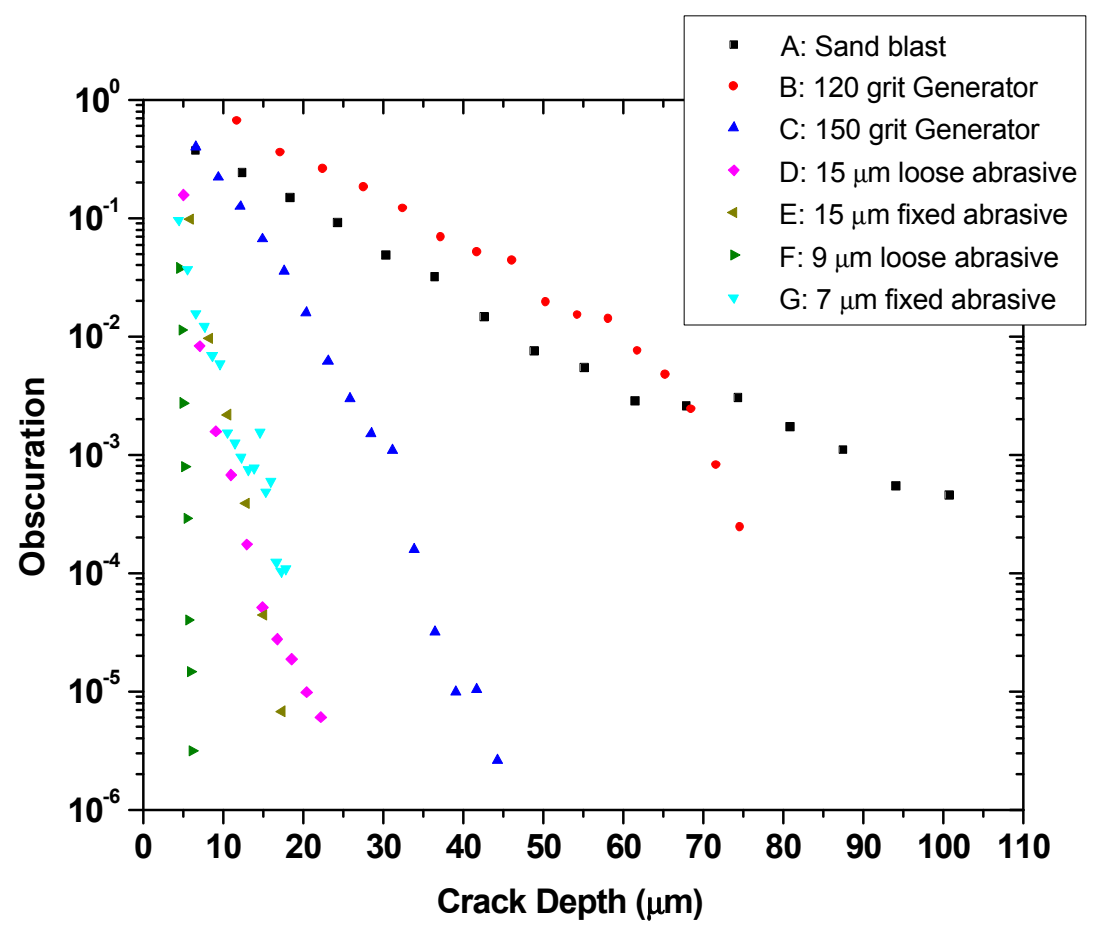

Figure 6: Cumulative distribution of crack depths, given as obscuration, observed by taper polishing, etching and image analysis of samples shown in Table 1. Note the truncation of the exponential decay of obscuration; particularly samples B and C (see text). 


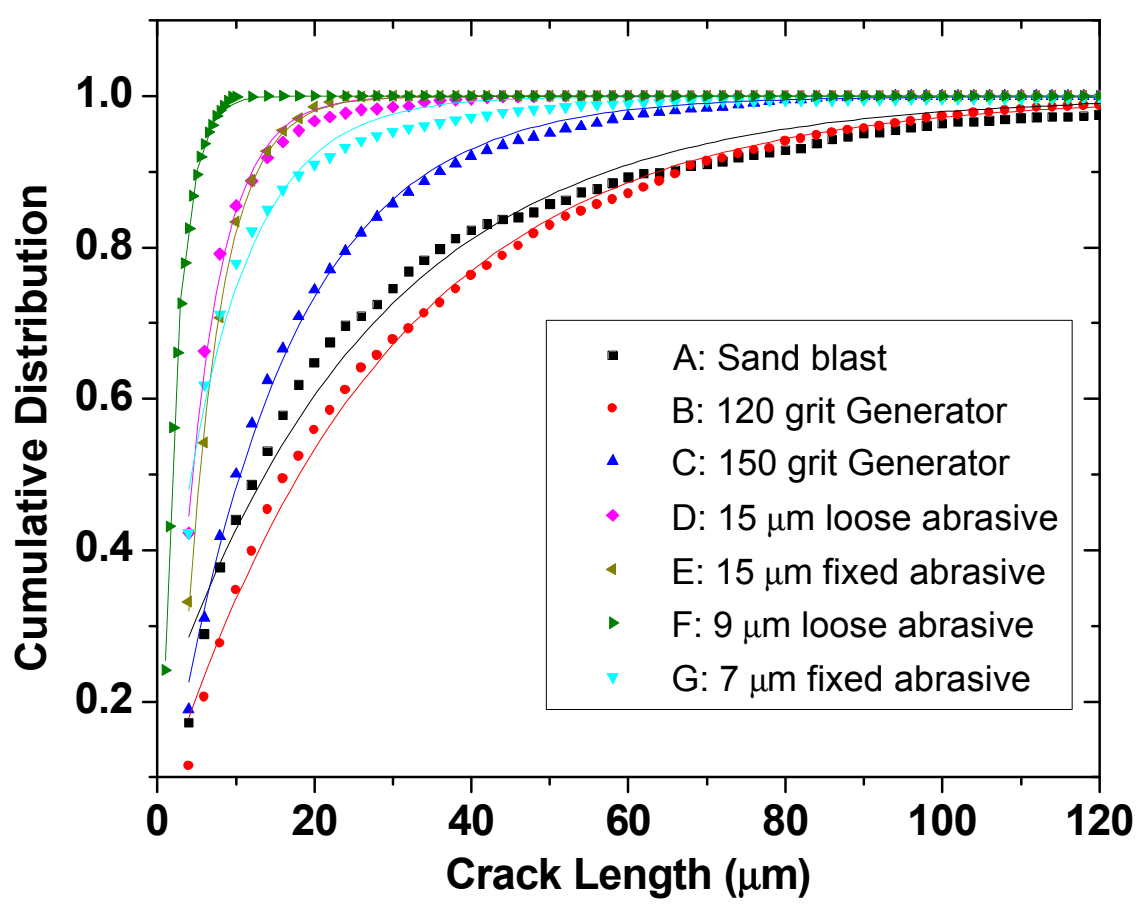

Figure 7: Cumulative distribution of crack lengths in samples A-G. Data points represent the experimentally determined crack length distribution found by the measurement of isolated subsurface cracks from each of the indicated samples. Each data set consisted of between 300 and 7000 individual fractures. The solid lines represent single exponential fits of each data set (see text).
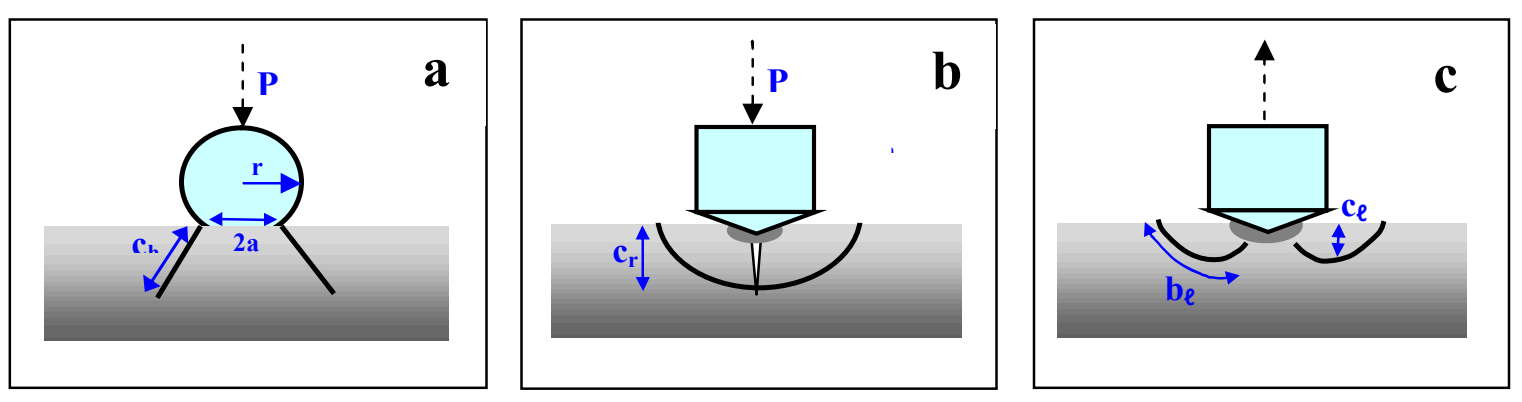

Figure 8: Schematic representation of the three basic fractures formed by static indentation. Hertzian cone cracks (a) form when a blunt indenter loads a brittle substrate. Radial cracks form beneath a plastically deformed zone resulting from a sharp indentation. Lateral cracks (c) form following the relaxation of the load on the plastically deformed region. (After Lawn ${ }^{16}$ ) 


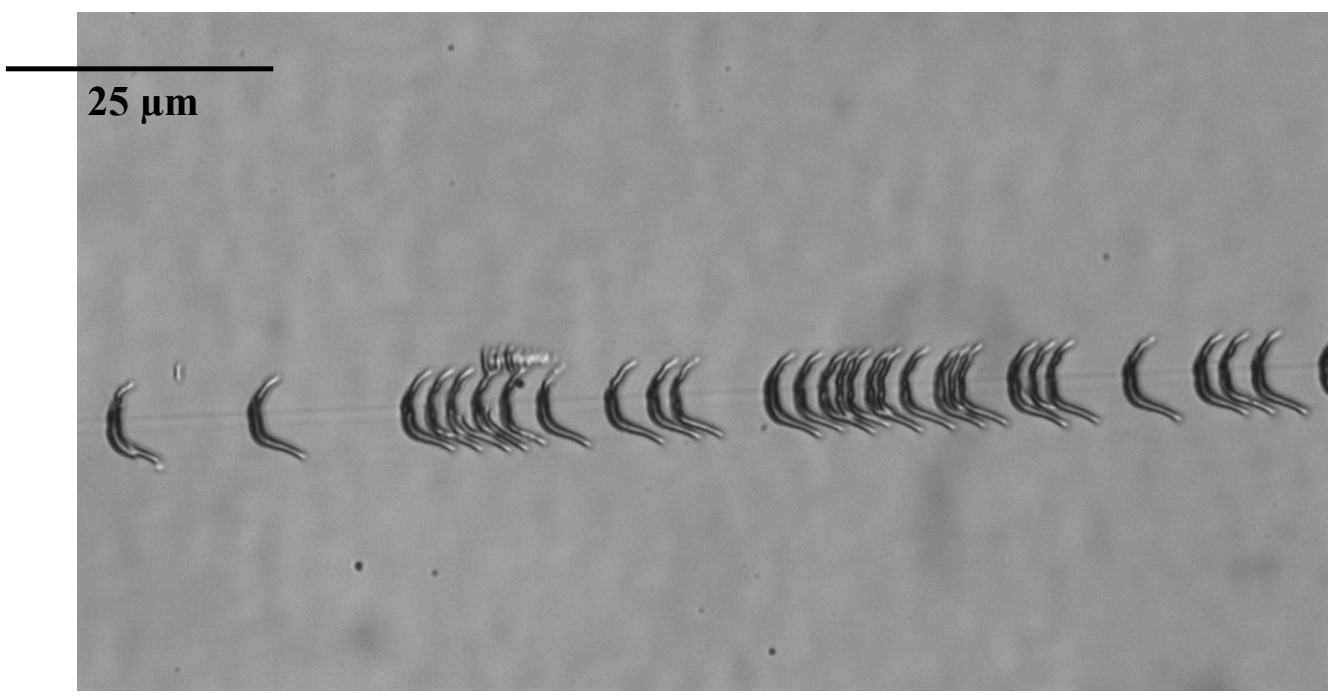

Figure 9: A series of trailing indentation fractures on a fused silica surface. The particle which caused this series of fractures moved from left to right. Following indentation, the resultant fractures were exposed by etching the substrate in 20:1 buffered oxide etch.

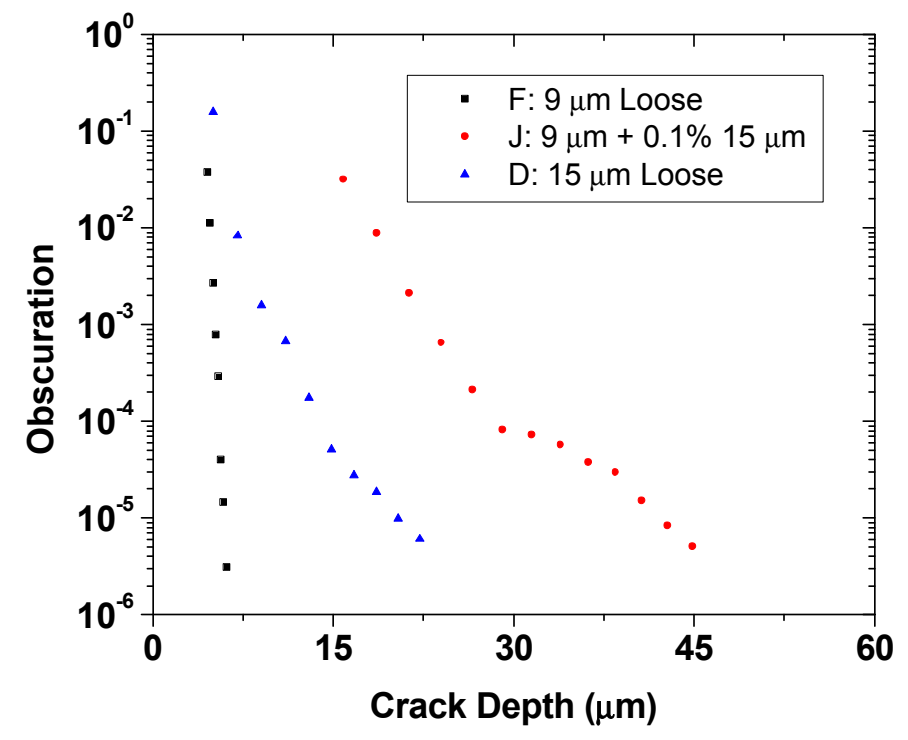

Figure 10: Distribution of subsurface damage in loose abrasive ground samples $\mathrm{F}\left(9 \mu \mathrm{m} \mathrm{Al}_{2} \mathrm{O}_{3}\right)$, D $\left(15 \mu \mathrm{m} \mathrm{Al} \mathrm{O}_{2}\right)$ and $\mathrm{J}\left(99.9 \% 9 \mu \mathrm{m}, 0.1 \% 15 \mu \mathrm{m} 15 \mu \mathrm{m} \mathrm{Al} \mathrm{O}_{3}\right)$. The increased depth of SSD observed in sample $\mathrm{J}$ results from the distribution of the total load among a smaller number of particles (see text). 


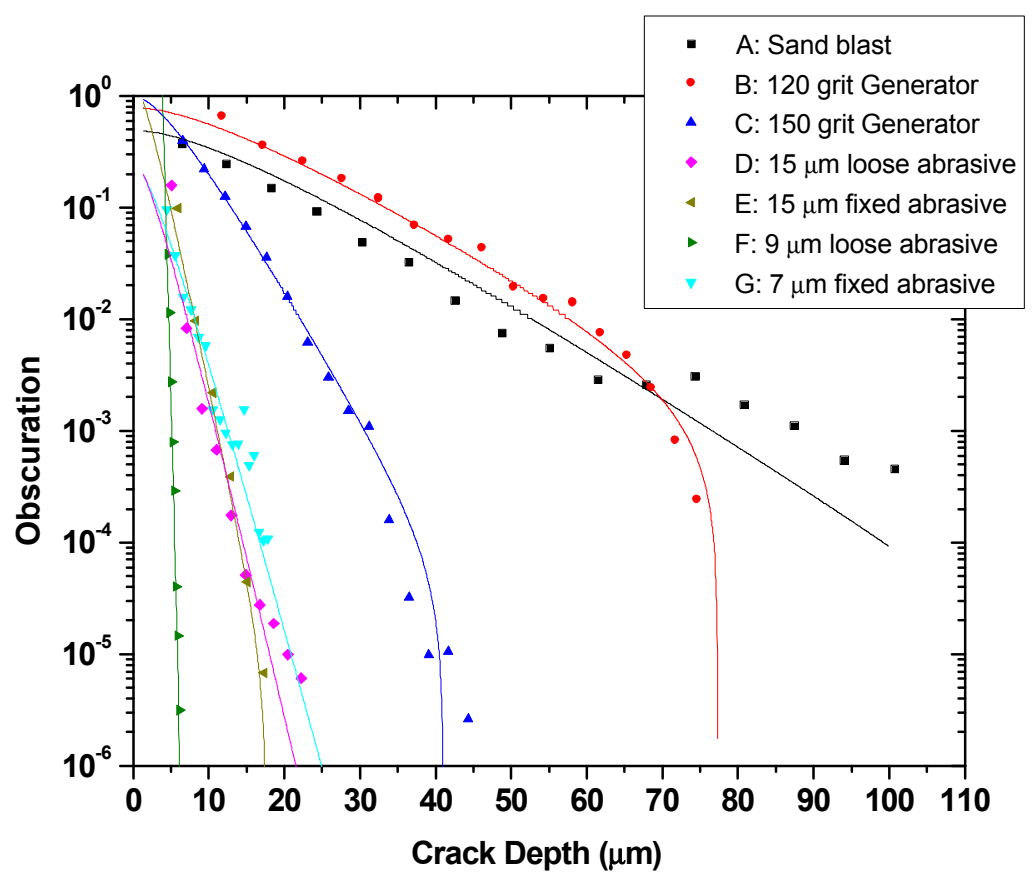

Figure 11: Comparison of directly measured distribution of obscuration (points) to fit of cumulative obscuration derived from crack length distribution (Equation 15). See Table 3 for fitting parameters.

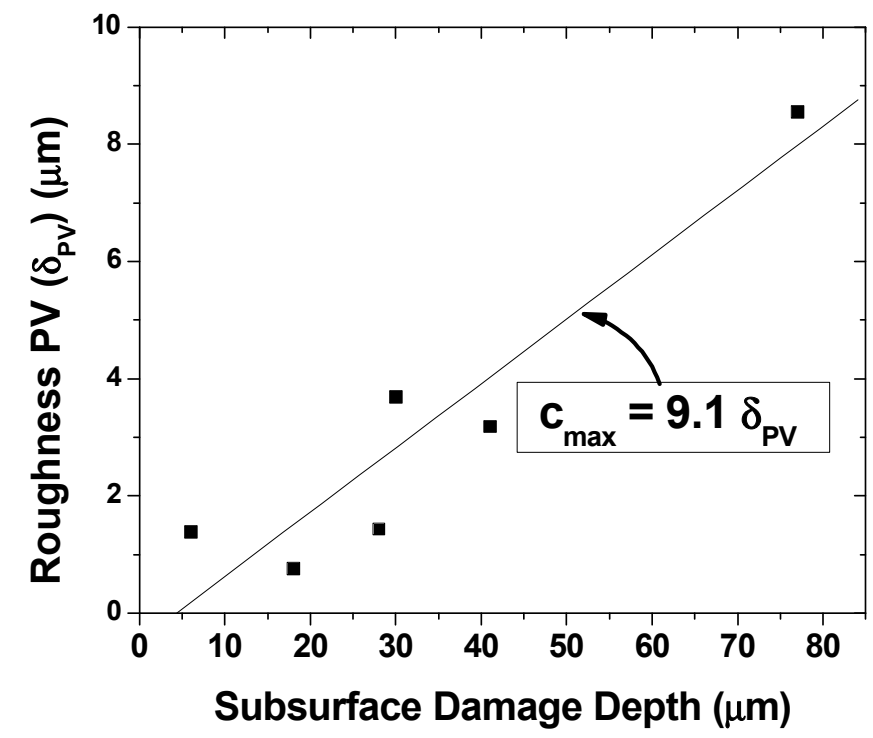

Figure 12: Correlation between peak to valley surface roughness and subsurface damage depth. Surface roughness measurements were performed using surface profilometery (see text). 


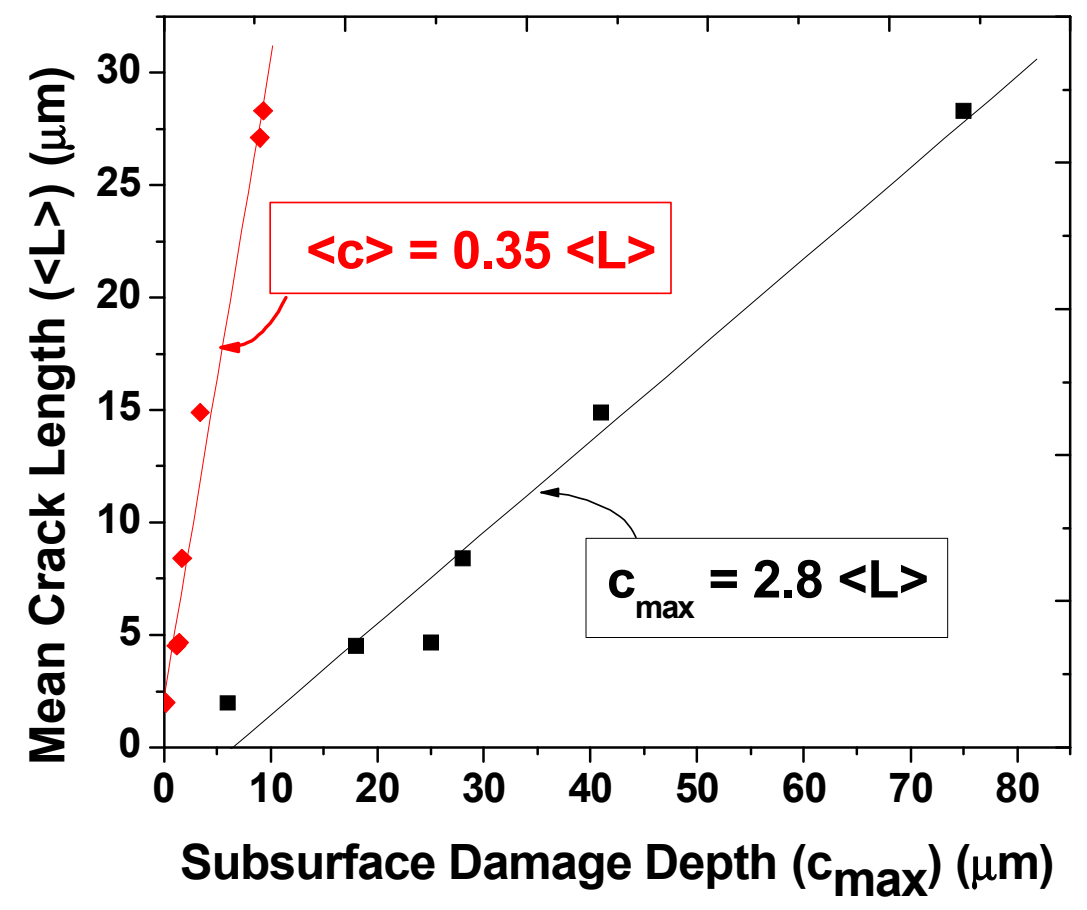

Figure 13: Correlation of maximum SSD depth $\left(\mathrm{c}_{\max }\right)$ and the average SSD depth $(<\mathrm{c}>)$ with the d mean crack length $(<\mathrm{L}>)$. 
Table 1: Conditions used During the Generation of Experimental Samples

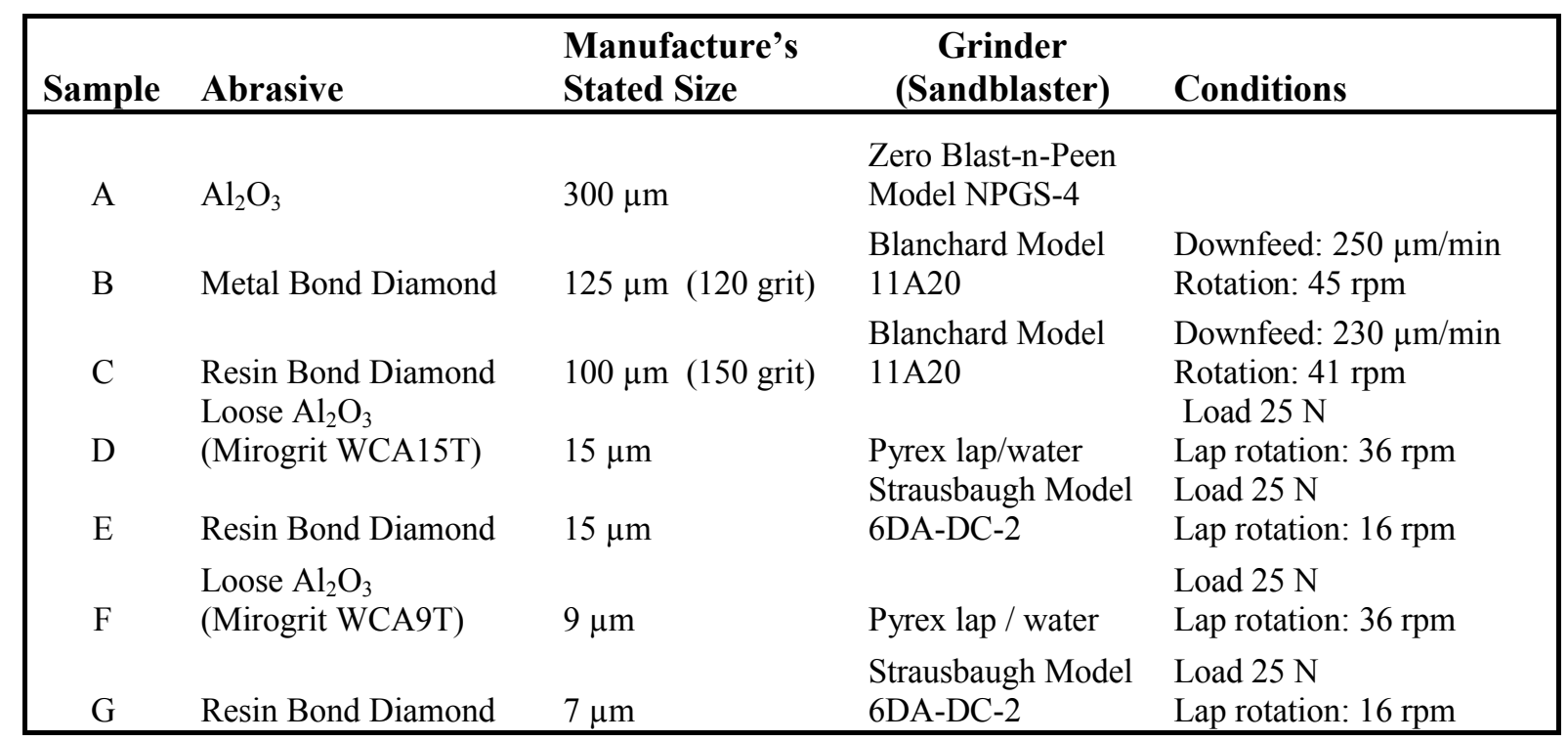

Table 2: Cumulative Crack length Distribution

Fitting Parameters

\begin{tabular}{|lcc|}
\hline Sample & A & $\langle\mathbf{L}>$ \\
\hline A: Sandblast & 0.83 & $27.1 \mu \mathrm{m}$ \\
B: 120 grit & 0.94 & $28.3 \mu \mathrm{m}$ \\
C: 320 grit & 1.01 & $14.9 \mu \mathrm{m}$ \\
D: $15 \mathrm{~mm}$ loose & 1.31 & $4.6 \mu \mathrm{m}$ \\
E: $15 \mathrm{~mm}$ fixed & 1.65 & $4.5 \mu \mathrm{m}$ \\
F: $9 \mathrm{~mm}$ loose & 1.23 & $2.0 \mu \mathrm{m}$ \\
G: $7 \mathrm{~mm}$ fixed & 0.83 & $8.4 \mu \mathrm{m}$ \\
\hline
\end{tabular}


Table 3: Fitting Parameters used to Fit Fracture Length Distribution Derived Obscuration to Experimental Data

\begin{tabular}{|lccc|}
\hline \multicolumn{1}{|c}{ Sample } & $\begin{array}{c}\text { Average Load per } \\
\text { particle }\left(\mathbf{P}_{\mathbf{T}} / \mathbf{N}_{\mathbf{L}}\right)\end{array}$ & $\begin{array}{c}\text { Average crack } \\
\text { Density }\left(\mathbf{n} / \mathbf{c m}^{\mathbf{2}}\right)\end{array}$ & $\begin{array}{c}\text { Max crack } \\
\text { length } \mathbf{L}_{\mathbf{m a x}}(\boldsymbol{\mu m})\end{array}$ \\
\hline A: Sandblast & 0.14 & $3 \times 10^{5}$ & 384 \\
B: 120 grit & 0.05 & $5 \times 10^{5}$ & 234 \\
C: 320 grit & 0.01 & $2 \times 10^{6}$ & 183 \\
D: $15 \mu \mathrm{m}$ loose & 0.005 & $1 \times 10^{6}$ & 100 \\
E: $15 \mu \mathrm{m}$ fixed & 0.003 & $4 \times 10^{6}$ & 68 \\
F: $9 \mu \mathrm{m}$ loose & 0.00008 & $3 \times 10^{15}$ & 68 \\
G: $7 \mu \mathrm{m}$ fixed & 0.0006 & $8 \times 10^{5}$ & nd \\
\hline
\end{tabular}




\section{References}

${ }^{1}$ B. Lawn " Fracture of Brittle Solids, - Second Edition, Chapter 2" Cambridge University Press, 1993

${ }^{2}$ V.D. Frechette "Failure Analysis of Brittle Materials" The American Ceramic Society" 1990

${ }^{3}$ D. Harris "Materials For Infrared Windows and Domes - Properties and Performance" SPIE Optical Engineering Press 1999

${ }^{4}$ M.D. Feit, and A. Rubenchik, "Influence of Subsurface Cracks on Laser Induced Surface Damage" Laser-Induced Damage in Optical Materials: 2003, Proceedings of SPIE Volume 5273 Gregory J. Exarhos, Arthur H. Guenther, Norbert Kaiser, Keith L. Lewis, M. J. Soileau, Christopher J. Stolz, Editors, June 2004, pp. 264-272

${ }^{5}$ F.W. Preston “The Structure of Abraded Glass Surfaces" Trans. of the Optical Soc." 23(1921) 141-164

${ }^{6}$ G.A.CM. Spierings, "Review: Wet Etching of Silicate Glasses in Hydrofluoric Acid Based Solutions” J. Mat. Sci. 28(1993) 6261-6273

${ }^{7}$ J.C. Lambropoulos, "From Abrasive Size to Subsurface Damage in Grinding" OSA Technical Digest (Optical Society of America, Washington D.C., 2000), pp. 17-18

${ }^{8}$ F.K. Aleinikov, "The Effect of Certain Physical and Mechanical Properties on the Grinding of Brittle Materials" in Sov. Phys. Tech. Phys. 27,2529-2538 (1957)

${ }^{9}$ D.F. Edwards and P.P. Hed "Optical Glass Fabrication Technology II: The Relationship Between Surface Roughness and Subsurface Damage” Appl. Optics 26, 4677-4680 (1987)

${ }^{10}$ J.C. Lambropoulos, Y. Li, P.D. Funkenbusch, and J. Ruckman "Non-contact Estimate of Grinding Induced Subsurface Damage" in Optical Instrumentation and Testing III, H.P. Stahl, ed., SPIE Proc. 3782, 41-50 (1999)

${ }^{11}$ Y. Zhou, P.D. Funkenbusch, DJ Quesnel, D.Golini, and A. Lindquist, "Effect of Etching and Imaging Mode on the measurement of Subsurface Damage in Microground Optical Glasses", J.Amer. Ceram. Soc., 3277-3280 (1994)

${ }^{12}$ F. Schimd, MB Smith, and CP Khattak, "Current Status of Sapphire Dome Production,” Proc. SPIE, 3060, 250-257 (1997)

13 J.A.Randi, J.C. Lambropoulos, and S.D. Jacobs, "Subsurface Damage in Some Crystalline Materials", Appl Optics 44(12), 2241-2249 (2005)

${ }^{14}$ S.R. Arrasmith, S.D. Jacobs, J.C. Lambropoulos, A. Maltsev, D. Golini, W.I. Kordonski, and E.E. Cleaveland, "The Use of Magnetorheological Finishing to Relieve Residual Stress and Subsurface 
Damage on Lapped Semiconductor Silicon Wafers" in Optical Manufacturing and Testing IV HP Stahl ed., Proc. SPIE 4451, 286-194 (2001)

${ }^{15}$ J.A. Menapace, P.J. Davis, W.A. Steele, T. I. Suratwala, P.E. Miller, and L.L. Wong "Utilization of Magnetorheological Finishing as a Diagnostic Tool for Investigating the Three-Dimensional Structure of Fractures in Fused Silica", Proceedings of the Boulder Damage Symposium XXXVII, In Press

${ }^{16}$ B. Lawn “ Fracture of Brittle Solids, - Second Edition, Chapter 8" Cambridge University Press, 1993

${ }^{17}$ M. Chaudhri, J. Mat. Sci. 15 (1980) 345

${ }^{18}$ B. Lawn " Partial Cone Crack Formation in a Brittle Material Loaded with a Sliding Spherical Indenter", Proc. of the Royal Society, Series A, Mathematical and Physical Science, 299(1458) (1967) 307

${ }^{19}$ H. Karow, "Fabrication Methods for Precision Optics" Chapter 3, John Wiley and Sons (1993)

${ }^{20}$ T.I. Suratwala, L.L. Wong, P.E. Miller, M.D Feit, J.A. Menapace and R.A. Steele, "Sub-surface Mechanical Damage Distributions During Grinding of Fused Silica" Proceeding of the $3^{\text {rd }}$ International Workshop on the Flow and Fracture of Advanced Glasses, In Press

${ }^{21}$ H. Hertz "Hertz's Miscellaneous Papers" Chapters 5 and 6, McMillian and Co. London 1896

${ }^{22}$ A.C. Fischer-Cripps, “The Hertzian Contact Surface” J. Mat. Sci. 34(1999) 129-137

${ }^{23}$ I. M. Hutching, "Tribology: Friction and Wear of Engineering Materials" Butterworth-Heinemann 1992

${ }^{24}$ J.C. Lambropoulos, "Micromechanics of Material-Removal Mechanisms from Brittle Surfaces" LLE Review (74) 131-138, 1998 